\title{
A comparative study of night-time enhancement of TEC at a low latitude station on storm and quiet nights including the local time, seasonal and solar activity dependence
}

\author{
K. Unnikrishnan ${ }^{1, *}$, R. Balachandran Nair ${ }^{2}$, and C. Venugopal ${ }^{3}$ \\ ${ }^{1}$ School of Pure and Applied Physics, Mahatma Gandhi University, Priyadarshini Hills, Kottayam - 686 560, Kerala, India \\ ${ }^{2}$ Department of Physics, College of Engineering, Kasargode - 671 541, Kerala, India \\ ${ }^{3}$ Department of Physics, University of Asmara, P O Box 1220, Asmara, Eritrea \\ *Present Address: Department of Physics, N. S. S. Hindu College, Changanacherry - 686 102, Kerala, India
}

Received: 18 January 2002 - Revised: 30 April 2002 - Accepted: 16 May 2002

\begin{abstract}
The main characteristics of night-time enhancements in TEC during magnetic storms are compared with those during quiet nights for different seasons and solar activity conditions at Palehua, a low latitude station during the period 1980-1989. We find that the mean amplitude has both a seasonal and solar activity dependence: in winter, the values are higher for weak storms as compared to those during quiet nights and increase with an increase in solar activity. In summer, the mean amplitude values during weak storms and quiet nights are almost equal. But during equinox, the mean amplitude values for quiet nights are greater than those during weak storms. The mean half-amplitude duration is higher during weak storms as compared to that during quiet nights in summer. However, during winter and equinox, the durations are almost equal for both quiet and weak storm nights. For the mean half-amplitude duration, the quiet night values for all the seasons and equinoctial weak storm values increase with an increase in solar activity. The occurrence frequency (in percent) of TEC enhancement during weak storms is greater than during quiet nights for all seasons. The mean amplitude, the mean half-amplitude duration and the occurrence frequency (in percent) of TEC enhancement values are higher during major storms as compared to those during quiet nights. The above parameters have their highest values during pre-midnight hours. From the data analysed, this behaviour is true in the case of major storms also.
\end{abstract}

Key words. Ionosphere (ionospheric disturbances; plasma convection) Magnetospheric physics (storms and substorms)

\section{Introduction}

It is well known that the total electron content (TEC) of the ionosphere does not decrease throughout the night as predicted by simple theory but shows anomalous enhancements

Correspondence to: $\mathrm{K}$. Unnikrishnan

(kaleekkalunni@yahoo.com) under a wide range of geophysical conditions (Arendt and Soicher, 1964; Balan and Rao, 1987; Balan et al., 1991). The various enhancement characteristics such as frequency of occurrence, time of occurrence, amplitude and duration are found to depend on location, season and solar activity. The effect of season, solar and magnetic activity on nighttime enhancements in TEC have been studied for low, mid and high latitudes (Young et al., 1970; Balan et al., 1986, 1991; Bailey et al., 1991, 1992; Lois et al., 1990; Sudhir Jain et al., 1995).

Lanzerotti et al. (1975) studied the latitudinal dependence of the changes in the ionospheric TEC during 12 magnetic storms by considering stations Hamilton and Arecibo. The storm effects at middle (Hamilton) and low (Arecibo) latitude stations were studied by considering three distinct time periods: (a) the daytime period on the first day, (b) the subsequent dusk to dawn period, and (c) the following days of the storm period. A pre local-midnight TEC ledge was frequently observed in the Arecibo storm data but seldom in Hamilton data. Nelson and Cogger (1971) studied the enhancement in TEC during geomagnetic storms at Arecibo by considering about 6 months of data from October 1968 to April 1969 and observed TEC enhancements in the afternoon or night during a magnetic disturbance.

The new aspect considered in this study is the influence of magnetic storms on night-time enhancement parameters. We analysed all the night-time enhancement parameters like amplitude, half-amplitude duration and occurrence frequency (in percent) of TEC enhancement during 212 magnetic storms at Palehua for a period of 10 years from 19801989 and their seasonal, solar activity and local time dependence were compared with those of quiet nights. Unlike the other low latitude stations of Lunping or Taiwan, Palehua is located where the geographic and geomagnetic equators are very close (differing by $<2^{\circ}$ ). Since the geographic and geomagnetic latitudes of Palehua are nearly equal to $19^{\circ} \mathrm{N}$, it's location, in general, is outside the equatorial anomaly crest. However, during high solar activity, the crest of the equato- 
rial anomaly can move to this location during evening hours of equinox.

We find that, during all the seasons, the occurrence frequency (in percent) of TEC enhancement during weak storms are greater than those during quiet nights. Also the mean amplitude, mean half-amplitude duration and mean occurrence frequency (in percent) of TEC enhancement values are higher during major storms as compared to those during quiet nights.

\section{Data and analysis}

The TEC data employed for this study, during the periods 1980-1984 and 1985-1989, were obtained respectively by the geostationary satellites ATS I and GOES 3 . We have confirmed that the sub ionospheric points of Palehua, for the ray paths from the satellites ATS 1 and GOES 3 during the periods 1980-1984 and 1985-1989, were nearly the same (Table 1) and that the first local night after storm commencement which we have considered (storm night) corresponds to the main phase (MP) of the storm.

We selected 212 magnetic storms during the period 19801989. Based on their $D_{s t}$ index, 160 storms were classified as weak storms with $D_{s t} \geq-100 \mathrm{nT}$ and major storms with $D_{s t} \leq-100 \mathrm{nT}$ (Tsurutani et al., 1990) which included both moderate and strong storms. The weak storms were then classified as winter (November, December, January and February), summer (May, June, July and August) and equinoctial (March, April, September and October) storms based on season. However, a similar classification of the major storms was not possible as a sufficient number of storms were not available during each season. We used the $10.7 \mathrm{~cm}$ solar flux as a better indicator of solar activity (Feynman and Gabriel, 2000). The weak storms during winter, summer and equinox were again categorised based on $10.7 \mathrm{~cm}$ solar flux groups like 51-100, 101-150, 151-200, 201-250. The nighttime enhancement parameters for each storm were found and their average for each of these groups was also found. A similar analysis was also carried out for major storms but without a seasonal classification. The night-time enhancement parameters were then plotted against $10.7 \mathrm{~cm}$ solar fluxes. Here, each data point corresponds to the sufficient number of storms, as given alongside the points for each solar flux group, ensuring the statistical reliability of the results. For comparison, seven quiet nights were selected prior to each storm with $A_{p}<10$. After identifying the quiet nights, the mean values of the night-time enhancement parameters were found and these were then compared with the corresponding stormtime values.

In characterising a night-time TEC enhancement, the same criterion as that adopted by Young et al. (1970) was applied. Accordingly, a night-time TEC enhancement was defined as the excess content $(\triangle T E C)$, which remained after the exponentially decaying background of the diurnal content was subtracted from the total content. The exponentially decaying background part of TEC was found by drawing a TEC



Fig. 1. Typical examples of night-time TEC variations during (a) major storms and (b) quiet times.

graph for each night as shown in Fig. 1 where the dashed curves represent the background part of TEC. The maximum difference between the enhanced TEC and the background content gave the excess content, which is called the "amplitude". For the present study, only those enhancements which had amplitudes greater than $20 \%$ of the background content were considered. The majority of the enhancements were found to have a single peak. However, in the case of enhancements having multiple peaks, only the prominent peak was considered for the statistical study.

To check whether the difference between the means during various seasons was significant, we performed the Student's " $t$ " test, defined by

$t=\left[\left(X_{1}-X_{2}\right) / S\right]\left[\left(n_{1} n_{2}\right) /\left(n_{1}+n_{2}\right)\right]^{1 / 2}$,

where $X_{1}$ and $X_{2}$ are the mean of the first and second samples; $n_{1}$ and $n_{2}$ their sizes and $S$ the combined standard deviation obtained by the formula,

$S=\left[\left(n_{1}-1\right) S_{1}^{2}+\left(n_{2}-1\right) S_{2}^{2} /\left(n_{1}+n_{2}-2\right)\right]^{1 / 2}$.

The condition for a significant difference between the mean values is that the $t_{\text {calculated }}>t_{\text {table. }}$. This condition was satisfied for various possible pairs like winter and summer mean values, summer and equinox mean values and winter and equinox mean values of amplitude, half-amplitude duration and the occurrence frequency (in percent) of TEC enhancement for all $10.7 \mathrm{~cm}$ solar flux groups. 
Table 1. Sub-ionospheric points at $4000 \mathrm{~km}$ height

\begin{tabular}{ccccc}
\hline Period & $\begin{array}{c}\text { Name of the } \\
\text { Satellite }\end{array}$ & $\begin{array}{c}\text { Geographic } \\
\text { Latitude }\end{array}$ & $\begin{array}{c}\text { Geomagnetic } \\
\text { Latitude }\end{array}$ & $\begin{array}{c}\text { Geographic } \\
\text { Longitude }\end{array}$ \\
\hline $1980-1984$ & ATS 1 & $18^{\circ} \mathrm{N}$ & $19.6^{\circ} \mathrm{N}$ & $206^{\circ} \mathrm{E}$ \\
$1985-1990$ & GOES 3 & $19^{\circ} \mathrm{N}$ & $19.6^{\circ} \mathrm{N}$ & $206^{\circ} \mathrm{E}$ \\
\hline
\end{tabular}

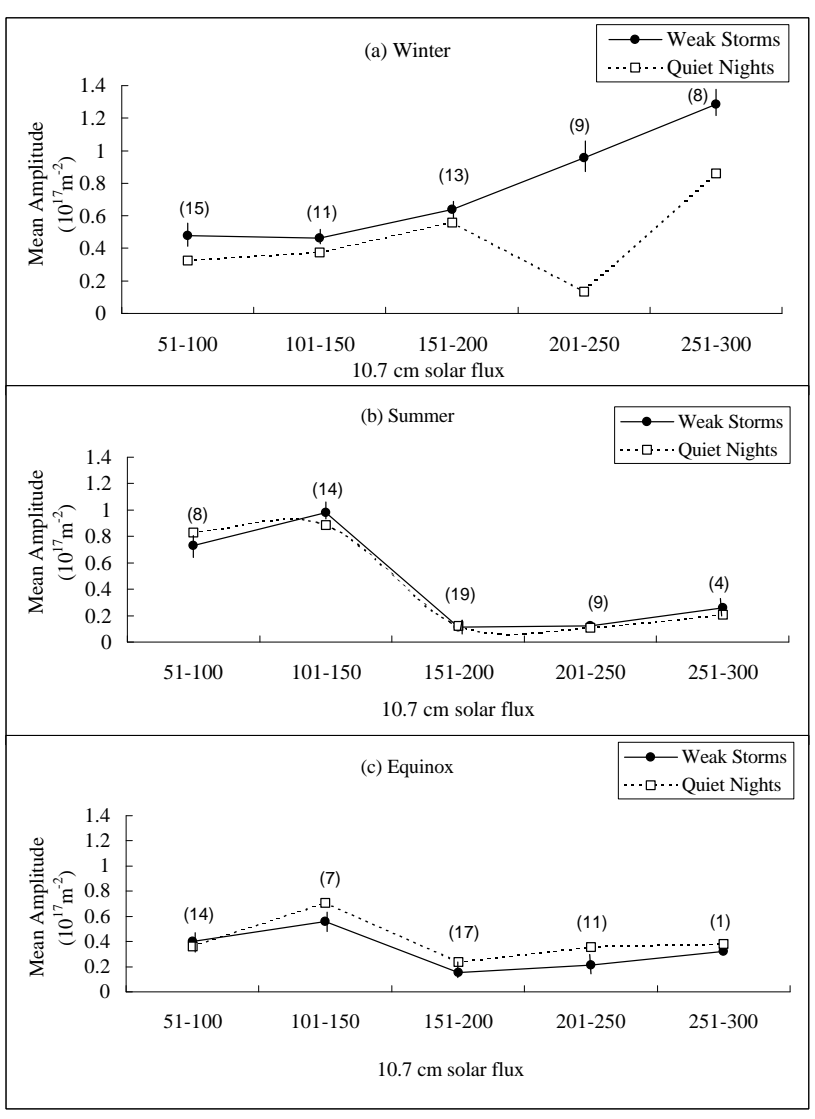

Fig. 2. The seasonal and solar activity variations of mean amplitude during weak storms (solid curves) and quiet nights (dashed curves). The numbers of weak storms are given in brackets beside the points for each solar flux group. The vertical bars represent the standard deviations.

\section{Results - comparison of various parameters during storms with those during quiet times}

\subsection{Mean amplitude}

Figure 1 represents typical variations in night-time total electron content during storms and quiet times respectively. Figure 2 depicts the variation of the mean amplitude, during weak storms and quiet nights with the $10.7 \mathrm{~cm}$ solar flux during winter, summer and equinox. The number of weak storms considered is given in brackets beside the points (in Fig. 2) for each solar flux group; this is applicable to Figs. 3 and 4 also. The vertical bars represent the standard devia- tions of the mean values.

We find that the mean amplitude has a seasonal as well as a solar activity dependence. In winter, the mean amplitude values are higher during weak storms as compared to those during quiet nights. Also, only during winter, these values, for both quiet nights and weak storms, increase with an increase in solar activity. In summer, these values during weak storms and quiet nights are almost equal. However, during equinox as opposed to winter, the mean amplitude values during quiet nights are higher than those during weak storms. The maximum values of the mean amplitude in winter, summer and equinox during the storms are: $1.287 \times$ $10^{17} \mathrm{~m}^{-2}, 0.987 \times 10^{17} \mathrm{~m}^{-2}$ and $0.557 \times 10^{17} \mathrm{~m}^{-2}$, respectively. The corresponding values during the quiet times are: $0.860 \times 10^{17} \mathrm{~m}^{-2}, 0.887 \times 10^{17} \mathrm{~m}^{-2}$ and $0.708 \times 10^{17} \mathrm{~m}^{-2}$, respectively. The maximum differences between the storm time mean amplitudes and those during the quiet nights are $0.823 \times 10^{17} \mathrm{~m}^{-2}$ and $0.099 \times 10^{17} \mathrm{~m}^{-2}$ in winter and summer, respectively.

We find the highest values of the mean amplitude to be in winter during weak storms and in summer during quiet nights.

Figure 6a depicts the variation of the mean amplitude with the $10.7 \mathrm{~cm}$ solar flux during all major storms and quiet nights. The number of strong storms considered in this study is again given in brackets beside the points for each solar flux group; again the vertical bars represent the standard deviations of the mean values.

We find that the mean amplitude values are generally higher during major storms as compared to those during quiet nights.

\subsection{Mean half-amplitude duration}

The seasonal and the solar activity variations of the halfamplitude duration during weak storms and quiet nights are exhibited in Fig. 3. In summer, the mean half-amplitude durations are generally higher during weak storms as compared to those during quiet nights. However, during winter and equinox these values are almost the same. In the case of the mean half-amplitude duration, both the quiet night values for all the seasons and the equinoctial weak storm values increase with an increase in solar activity. The maximum values of the mean half-amplitude duration in winter, summer and equinox during weak storms are: $130 \mathrm{~min}, 149 \mathrm{~min}$ and $166 \mathrm{~min}$, respectively; similarly during quiet nights these are: $102 \mathrm{~min}, 133 \mathrm{~min}$ and $162 \mathrm{~min}$, respectively. The maximum differences between the storm time and the quiet night 


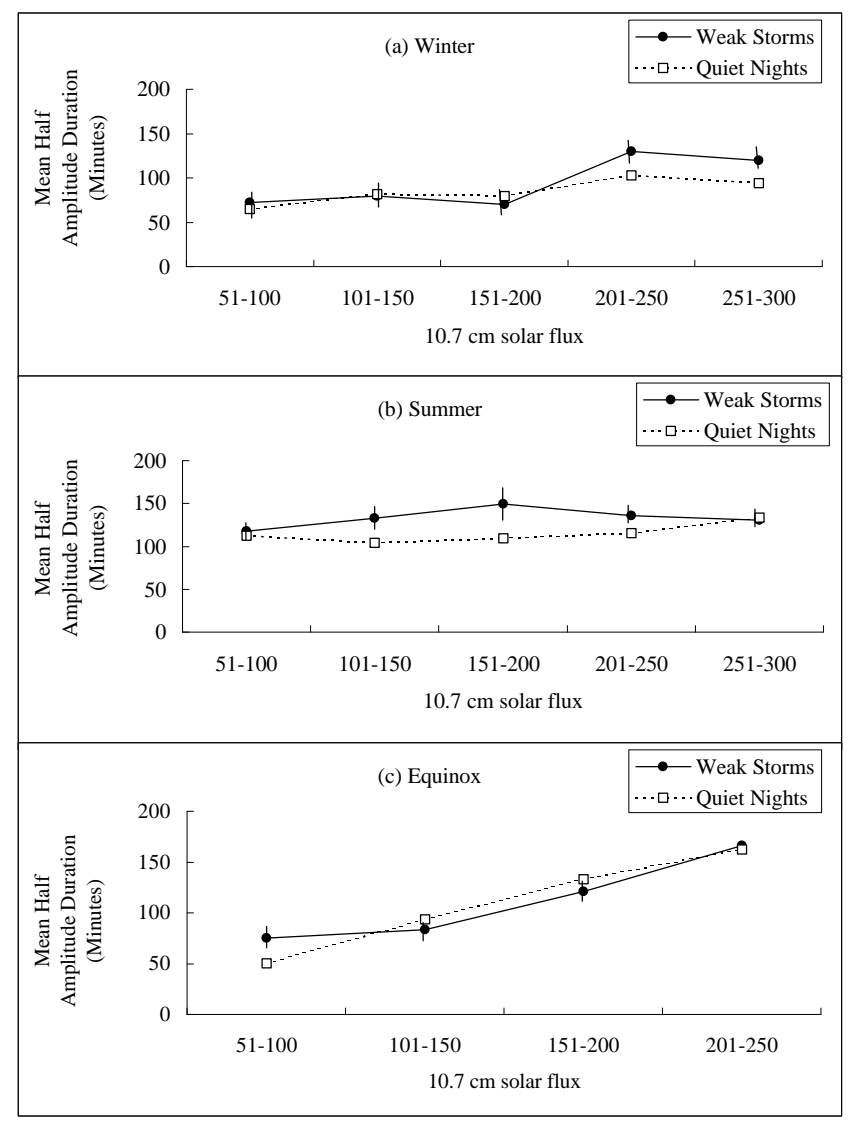

Fig. 3. The seasonal and solar activity variations of the mean halfamplitude duration during weak storms (solid curves) and quiet nights (dashed curves). The vertical bars represent the standard deviations.

mean half-amplitude durations are 28 and $40 \mathrm{~min}$, respectively, during winter and summer. Figure $6 \mathrm{~b}$ depicts the variation of the mean half-amplitude duration during all major storms and quiet nights with the $10.7 \mathrm{~cm}$ solar flux. The halfamplitude duration values are also generally higher during major storms as compared to those during quiet nights.

\subsection{The occurrence frequency (in percent) of TEC en- hancement}

In Fig. 4, the seasonal and solar activity variations of the occurrence frequency (in percent) of TEC enhancement during weak storms and quiet nights are shown. For all the seasons, the occurrence frequency (in percent) of TEC enhancements during weak storms is greater than those during quiet nights. From Fig. $6 \mathrm{c}$ we find the same to be true during the major storms also. The maximum occurrence frequency (in percent) of TEC enhancement in winter, equinox and summer during weak storms is $100 \%$. The same parameter during quiet nights for winter, summer and equinox is respectively $78 \%, 88 \%$ and $86 \%$. Also, the values for the maximum difference in the occurrence frequency (in percent) of TEC enhancement between storm time and quiet times during win-
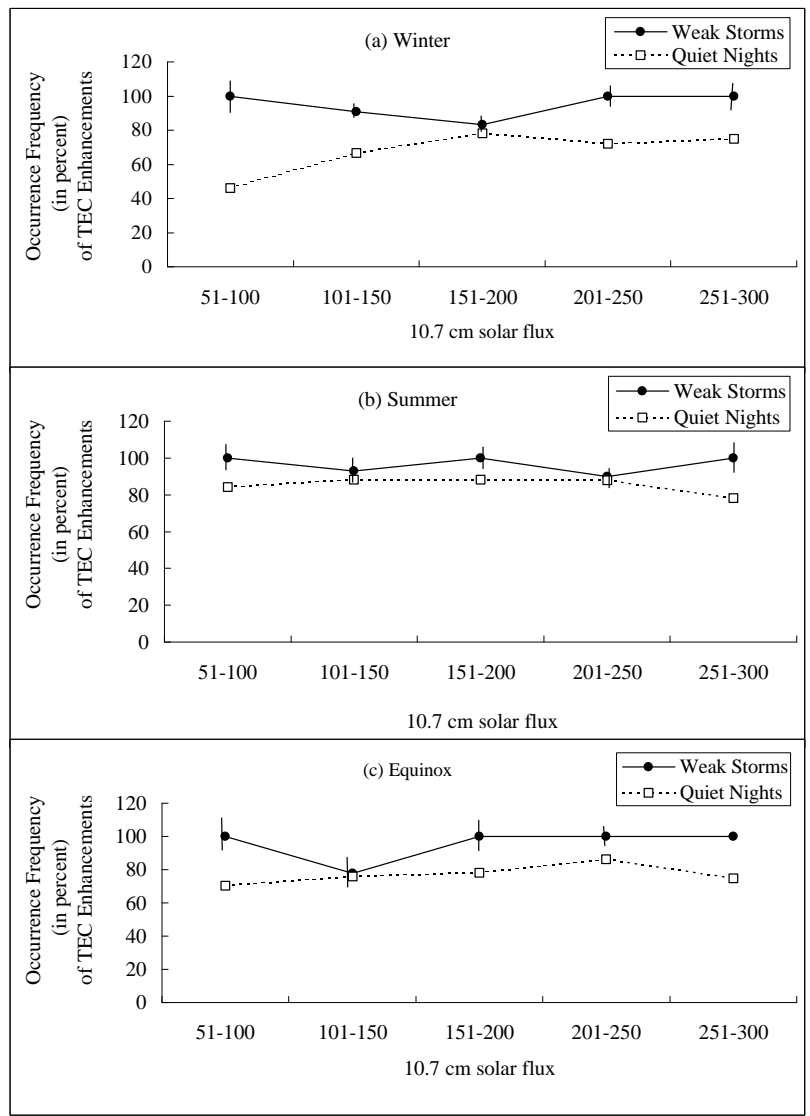

Fig. 4. The seasonal and solar activity variations of the occurrence frequency (in percent) of TEC enhancement during weak storms (solid curves) and quiet nights (dashed curves). The vertical bars represent the standard deviations.

ter, summer and equinox are $54 \%, 22 \%$ and $30 \%$, respectively.

It should be noted that, we have focussed on the maximum (or highest) values of the mean amplitude, duration, and occurrence frequency (in percent) of TEC enhancement for each season in order to show their seasonal dependence.

\subsection{Local time dependence}

Figure 5, represents the local time distribution of the mean amplitude, mean half-amplitude duration and occurrence frequency (in percent) of TEC enhancement during weak storms and quiet nights. All these parameters have their highest values during the pre-midnight hours. From the data analysed, this behaviour is true for major storms also.

\section{Discussion}

The results presented here provide a reasonably comprehensive picture of the effects of solar activity, strength of storm, season and local time of TEC maximisation, on various characteristics of night-time enhancements during magnetic storms. Previous studies on night-time enhancement 


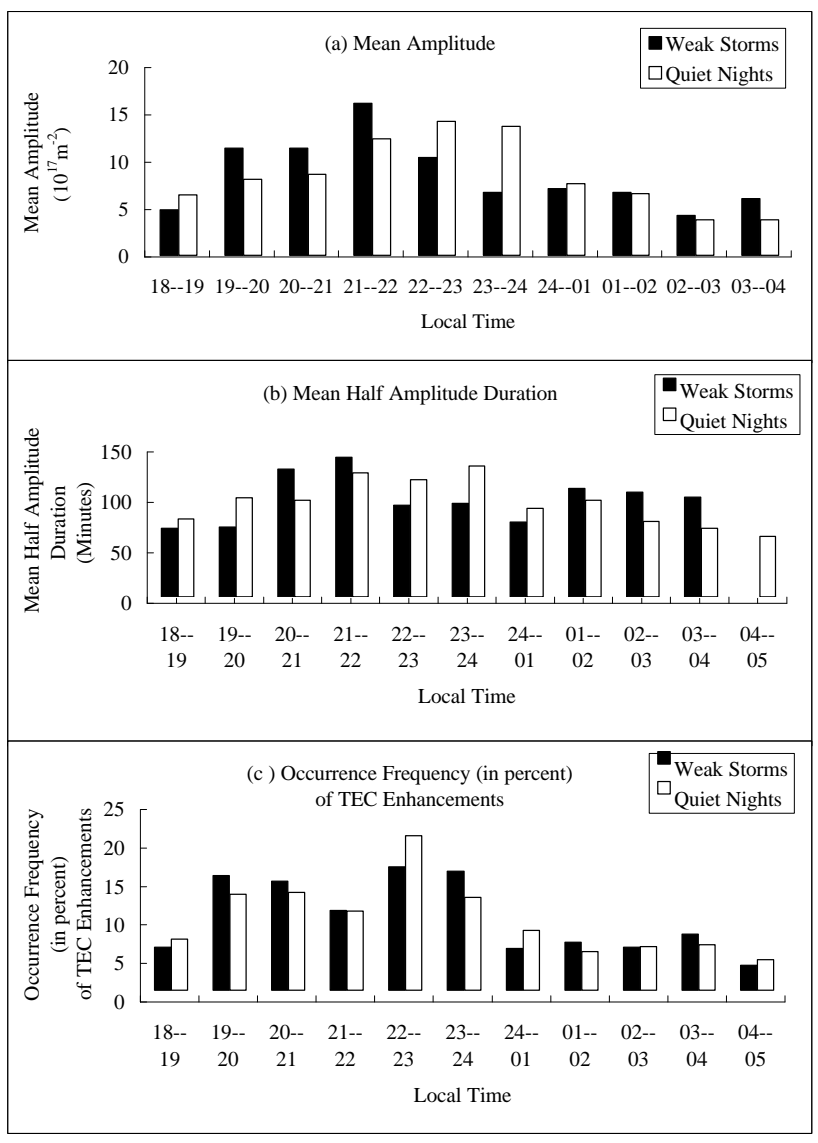

Fig. 5. Local time distribution of (a) the mean amplitude (b) mean half-amplitude and (c) the occurrence frequency (in percent) of TEC enhancement during weak storms and quiet nights.

were generally conducted by selecting a particular period, which included quiet as well as disturbed nights (Young et al., 1970; Essex and Klobuchar, 1980; Balan et al., 1986). The latitudinal dependence of night-time enhancements was also studied by selecting quiet and magnetically disturbed nights (Balan et al., 1991).

Balan et al. (1986) observed that at the low latitude station Hawaii, $77 \%$ of the nights had TEC enhancements of which 55\% occurred during pre-midnight hours and $22 \%$ during post midnight hours during a solar maximum year. However, during a solar minimum year, only $16 \%$ of the nights had TEC enhancements of which $7 \%$ occurred during pre-midnight hours and $9 \%$ during post midnight hours. They also found that the most probable time of maximisation was 21:00-22:00 LT during winter and 01:00-02:00 LT during summer while equinox had no such definite probable time for maximisation. Nelson and Cogger (1971) who observed TEC enhancements in the afternoon or night during a magnetic disturbance could associate these enhancements with large negative excursions in the $H$ component of the local geomagnetic field induced by the ring current.

Sudhir Jain et al. (1995) conducted a study on night-time enhancements at Lunping and found that a significant posi-

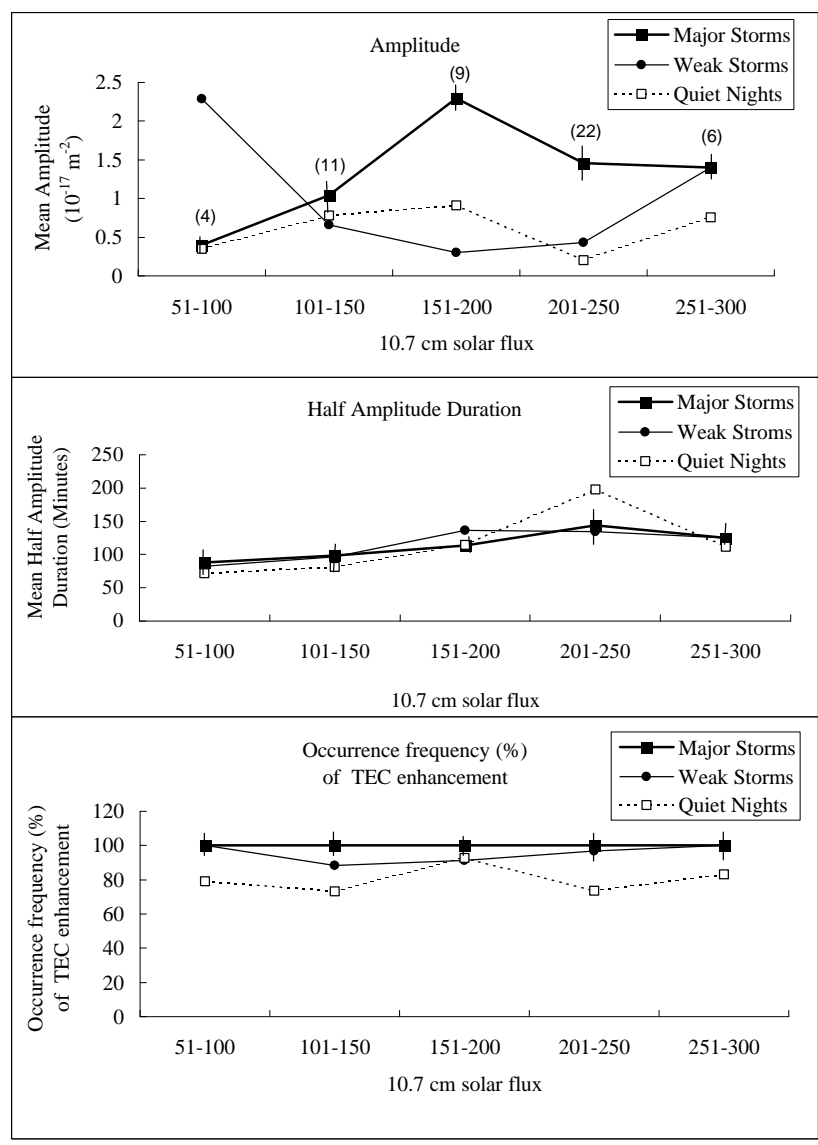

Fig. 6. The solar activity variations of (a) mean amplitude (b) mean half-amplitude and (c) the occurrence frequency (in percent) of TEC enhancement during major storms (bold curves), weak storms (solid curves) and those of quiet nights (dashed curves). The numbers of major storms are given in brackets beside the points for each solar flux group. The vertical bars represent the standard deviations.

tive correlation existed between amplitude and solar activity while that between amplitude and magnetic activity was negligible. While they found that the dependence of occurrence of night time enhancement on solar activity was negative, no such dependence is found in our study. Also, while their enhancements were mainly a post midnight phenomenon, in the present study pre-midnight enhancement is more prominent.

The plasmaspheric model of Bailey and Sellek (1990) suggests that the characteristics of night-time enhancements in TEC are modulated by night-time neutral winds (Bailey et al., 1991). Also, the $\boldsymbol{E} \times \boldsymbol{B}$ drift is quite sensitive to the magnitude and direction of the $\boldsymbol{B}$ field (Sudhir Jain et al., 1995). The stations, Palehua, in the present study and Lunping have different magnetic declinations and hence different mean magnetic fields which could alter the modulating effects of the neutral winds. This could be a possible reason for the differing trends exhibited by Palehua and Lunping.

The results presented here for quiet nights are consistent with similar studies: previous studies (Young et al., 1970; Balan et al., 1986, 1991) observed that the occurrence frequency (in percent) of TEC enhancement, amplitude and 
half-amplitude duration all had a high positive correlation with solar activity at low latitudes, especially for quiet nights. This study also shows that the mean amplitude $\left(\Delta \mathrm{TEC}_{\max }\right)$ during winter and the mean half-amplitude duration $(\tau)$ for winter, summer and equinox have a general positive correlation with solar activity during quiet nights. However, the occurrence frequency (in percent) of TEC enhancement does not show such a correlation. The observation that the times of occurrence of peak enhancements are during pre-midnight hours for all seasons during quiet nights is also consistent with earlier results (Balan et al., 1986, 1991).

Potential source mechanisms for the observed TEC enhancements have been discussed by several authors (Young et al., 1970; Leitinger et al., 1982; Balan and Rao, 1987; Balan et al., 1991). The observed features, particularly the time of occurrence and solar activity dependence of the enhancements at different latitudes, indicate that the enhancements are caused by different mechanisms at different latitudes. The important mechanisms are: (1) electrodynamic drifts and plasma motion due to neutral winds, (2) plasma diffusion from protonosphere, (3) cross $-L$ plasmaspheric compression and subsequent enhancement in plasmasphereionosphere plasma flow, (4) plasma transfer from conjugate ionosphere, (5) movement of the mid-latitude trough and (6) corpuscular ionisation.

Many excellent reviews on the current understanding of ionospheric storms have been published in the last few years (Abdu 1997; Fuller-Rowell et al., 1997; Prölss, 1997; Rees 1996; Schunk and Sojka, 1996). The possible processes which might contribute to the magnetic storm associated ionospheric variations are: (1) electromagnetic drift associated with stormtime electric field (2) enhanced thermospheric circulation (waves and winds) generated by auroral zone heating during magnetic storms and the consequent increased loss rate, (3) compression of plasmasphere by enhanced solar wind and (4) changes in atmospheric composition due to enhanced thermospheric circulation.

At low latitudes the electrodynamic $\boldsymbol{E} \times \boldsymbol{B}$ drifts are very effective in transporting ionisation in the ionosphere. It has also been established that, at low latitudes, atomic oxygen is enhanced by transport from higher latitudes for the upwelling in the auroral oval. This, combined with the upward lifting of the ionised and neutral air winds, would give prolonged enhancements in electron density and TEC (Reddy et al., 1990).

Previous studies indicate that the electrodynamic drifts and plasma motion due to the neutral winds are the probable processes behind the night-time enhancement in TEC. Also, the solar cycle variations are such that the increase in upward $\boldsymbol{E} \times \boldsymbol{B}$ drift velocity becomes greater with an increase in solar activity. This could be the possible reason for the observed increase in amplitude with $10.7 \mathrm{~cm}$ solar flux (F10.7) during the winter weak storms (Fejer et al., 1979; Namboothiri et al., 1989; Balan et al.,1991; Sudhir Jain et al., 1995).

By using a mathematical model of the equatorial anomaly region, Anderson and Klobuchar (1983) have shown that the post sunset increase in the upward $\boldsymbol{E} \times \boldsymbol{B}$ drift velocity is primarily responsible for the post sunset increase in TEC observed at the equatorial anomaly crest station, Ascension Island. The inclusion of a meridional neutral air wind in the model modulates the post sunset peak in the modelled TEC so that the modelled and observed TEC are in closer agreement.

Fuller-Rowell et al. (1996) clarified the main seasonal changes associated with thermosphere/ionosphere storms. Simulations from the Coupled Thermosphere Ionosphere Model (CTIM) for solstice and equinox showed in detail how the prevailing summer to winter circulation restricts the equatorward movement of composition changes in the winter hemisphere and reinforces it in summer. The positive phase of the storm in winter and the negative phase of the storm in summer were explained by composition changes, downwelling in winter and upwelling in summer. The study conducted by Field et al. (1998) using the Coupled Thermosphere Ionosphere Plasmasphere (CTIP) model also supports the idea that composition changes can explain both the negative and positive storm effects through upwelling and downwelling which produces changes in $\mathrm{O} / \mathrm{N}_{2}$ at fixed pressure levels. This positive storm effect which occurs so often in winter may be the reason for higher amplitude values during weak storms in winter as compared to quiet night values.

It is well known that the electrodynamic drift and winds are prominent causes which produce storm associated ionospheric changes at low latitudes. At the same time these are also the two probable processes behind night-time enhancements in TEC. When we consider the night-time enhancements in TEC during storms, the effect of these mechanisms would be very predominant. This may be a possible reason for large values of night-time enhancements in TEC ( $>20 \%$ of the back ground content) during storms as compared to quiet nights; hence storm time occurrence of night-time enhancements would be higher than that of quiet nights.

The direction of the meridional neutral air wind is, in general, poleward during the day and equatorward during the night. At low latitudes the maximum velocity of the equatorward wind occurs during pre-midnight hours (Hedin et al., 1988; Krishna Murthy et al., 1990). The interaction between an equatorward neutral air wind and the ionospheric plasma raises the ionisation to altitudes of lower chemical loss. This reduces the loss of ionisation so that the extra ionisation added to the topside ionosphere by enhanced fountain effect can exhibit enhancements in TEC. Since plasma motion due to neutral winds is one of the mechanisms behind night-time enhancement, this could explain why the most probable local time of maximum enhancement and highest values of enhancement parameters occur during pre-midnight hours.

In general, it can be stated that, if the behaviour of the height of the layer is not significantly affected by the magnetic storm, without an additional source of ionisation the electron content would decay on disturbed days exactly as it does on undisturbed days (Nelson and Cogger, 1971). This could be the reason for the quiet night amplitude appearing to be almost equal or even slightly greater than those of weak storms for certain $10.7 \mathrm{~cm}$ solar flux groups. 
During storms, both positive and negative storm effects influence the night-time enhancements in TEC. During summer, the local thermospheric temperature is higher and hence the recombination losses are higher than in winter. This leads to a reduction of the enhancement in TEC in summer (Unnikrishnan et al., 1996), which may be a possible reason for the decrease in amplitude $\left(\triangle \mathrm{TEC}_{\max }\right)$, especially when $10.7 \mathrm{~cm}$ solar flux $>150$ units, for weak storms. Also, during magnetic storms, the plasmasphere is compressed causing the mid-latitude trough to move to lower latitudes. On either side of the trough, TEC enhancements are strong. On the equatorward side the dumping of plasma into the topside ionosphere will be caused by magnetospheric compression, which in turn produces strong enhancements in TEC. This may also influence the night-time enhancements associated with storms (Balan et al., 1991).

\section{Conclusions}

The main characteristics of night-time enhancements during magnetic storms are compared with those during quiet nights for different seasons and solar activity conditions at a low latitude station, Palehua, during the period 1980-1989. The main conclusions of this study are:

1. The mean amplitude has a seasonal as well as a solar activity dependence. In winter, the mean amplitude values are higher for weak storms as compared to those during quiet nights. The mean amplitude values, for both quiet nights and weak storms, increase with an increase in solar activity only during winter. In summer, the mean amplitude values, during both weak storm and quiet nights, are almost equal. But during equinox, the mean amplitude values for quiet nights are greater compared to those during weak storms.

2. The mean half-amplitude durations are higher during weak storms as compared to those during quiet nights during summer. However, during winter and equinox, the durations are almost equal for both quiet and weak storm nights. The quiet night values, for all seasons, and the equinoctial weak storm values of this parameter increase with an increase in solar activity.

3. The occurrence frequency (in percent) of TEC enhancements during weak storms is greater than during quiet nights, for all seasons.

4. The mean amplitude, mean half-amplitude duration and the occurrence frequency (in percent) values are higher during major storms as compared to those during quiet nights.

5. The mean amplitude, the mean half-amplitude duration and the occurrence frequency (in percent) of TEC enhancements have their highest values during premidnight hours, for all the seasons. From the data analysed, this behaviour is also true in the case of major storms.
Acknowledgements. The authors would like to thank N. Balan, Radio and Space Physics Group, Department of Physics, University of Wales, UK for useful discussions. They also express their sincere thanks to the World Data Centre-A for Solar Terrestrial Physics, Boulder, Colorado, USA, for kindly providing the data required for this study.

Topical Editor M. Lester thanks K. Shiokawa and J. J. Sastri for their help in evaluating this paper.

\section{References}

Abdu, M. A.: Major phenomena of the equatorial ionosphere/thermosphere system under disturbed condition, J. Atmos. Solar-Terr. Phys., 59, 1505-1519, 1997.

Anderson, D. N. and Klobuchar, J. A.: Modelling the total electron content observations above Ascension Island, J. Geophys. Res., 88, 8020-8024, 1983.

Arendt, P. R. and Soicher, H.: Downward electron flux at $100 \mathrm{~km}$ altitude from electron content measurement at mid latitude, $\mathrm{Na}$ ture, 204, 984-985,1964.

Bailey, G. J. and Sellek, R.: A mathematical model of the Earth's plasmasphere and its application in a study of $\mathrm{He}^{+}$at $L=3.0$, Ann. Geophysicae, 8, 171-190, 1990.

Bailey, G. J., Sellek, R., and Balan, N.: The effect of interhemispheric coupling on night-time enhancements in ionospheric total electron content during winter at solar minimum, Ann. Geophysicae, 9, 738-747, 1991.

Bailey, G. J., Sellek, R., and Balan, N.: Night-time enhancements in TEC during winter at solar minimum: the effect of the conjugate hemisphere, Adv. Space Res., 12, 309-312, 1992.

Balan, N. and Rao, P. B.: Latitudinal variations of night-time enhancements in total electron content, J. Geophys. Res., 92, A4, 3436-3440, 1987.

Balan, N., Rao, P. B., and Iyer, K. N.: Seasonal and solar variations of night-time anomalous enhancements in total electron content. Proc. Indian Acad. Sci., 95, 409-416, 1986.

Balan, N., Bailey, G. J., and Balachandran Nair, R.: Solar and magnetic activity effects on the latitudinal variations of night-time TEC enhancement, Ann. Geophysicae, 9, 60-69, 1991.

Essex, D. A. and Klobuchar, J. A.: Mid latitude winter night-time increases in the total electron content of the ionosphere, J. Geophys. Res., 85, 6011-6020, 1980.

Fejer, B. C., Farley, D. T., Woodman, R. F., and Calderon, C.: Dependence of equatorial F-region vertical drifts on season and solar cycle. J. Geophys. Res., 84, 5792-5796, 1979.

Feynman, J. and Gabriel, S. B.: On space weather consequences and predictions, J. Geophys. Res., 105, A5, 10 543-10 564, 2000.

Field, P. R., Rishbeth, H., Moffett, R. J., Idenden, D. W., FullerRowell, T. J., Millward, G. H., and Aylward, A. D.: Modelling composition changes in F-layer storms, J. Atmos. Solar-Terr. Phys., 60, 523-543, 1998.

Fuller-Rowell, T. J., Codrescu, M. V., Rishbeth, H., Moffet, R. J., and Quegan, S.: Seasonal response of the thermosphere and ionosphere to geomagnetic storms, J. Geophys. Res., 101, 23432353, 1996.

Fuller-Rowell, T. J., Codrescu, M. V., Roble, R. G., and Richmond, A. D.: How does the thermosphere and ionosphere react to a geomagnetic storm, Magnetic storms, Geophysical Monograph, 98, AGU, Washington, D.C., 1997.

Hedin, A. E., Spencer, N. W., and Killeen, T. C.: Empirical global model of upper thermosphere winds based on atmosphere and 
dynamics explorer satellite data, J. Geophys. Res., 93, 99599978, 1988.

Krishna Murthy, B. V., Hari, S. S., and Somayajulu, V. V.: Nighttime equatorial thermospheric meridional winds from ionospheric HF data, J. Geophys. Res., 95, 4307-4310, 1990.

Lanzerotti, L. J., Cogger, L. L., and Mendillo, M.: Latitude dependence of ionosphere total electron content: Observations during sudden commencement storms, J. Geophys. Res., 80, 12871306, 1975.

Leitinger, R., Hartmann, G. K., and Degenhardt, W.: Ionosphere of the southern boundary of diffuse aurora, J. Atmos. Terr. Phys., 44, 369-374, 1982.

Lois, L., Peres, X., Latso, B., Yakovski, N., and Landrok, R.: Night time increases of ionisation in the F-region above Cuba: the relation to solar activity, Geomagnetism and Aeronomy, 301, 76-82, 1990.

Namboothiri, S. P., Balan, N., and Rao, P. B.: Vertical plasma drifts in the F-region at the magnetic equator, J. Geophys. Res., 94, 12 055-12 060, 1989.

Nelson, G. I. and Cogger, L. L.: Enhancements in electron content at Arecibo during geomagnetic storms, Planet. Space Sci., 99, 761-775, 1971.

Prölss, G. W.: Magnetic storm associated perturbations of the upper atmosphere, Magnetic storms, Geophysical Monograph, 98,
AGU, Washington, D.C., 1997.

Reddy, C. A., Fukao, S., Takami, T., Yamamoto, M., Tsuda, T., Nakamura, T., and Kato, S.: A MU radar based study of mid latitude F-region response to a geomagnetic disturbance, J. Geophys. Res., 95, 21 077-21 083, 1990.

Rees, D.: Observations and modelling of ionospheric and thermospheric disturbance during major geomagnetic storms - a review, J. Atmos. Terr. Phys., 57, 1433-1457, 1996.

Schunk, R. W. and Sojka, J. J.: Ionosphere-thermosphere space weather issues, J. Atmos. Terr. Phys., 58, 1527-1574, 1996.

Sudhir Jain, Vijay, S. K., Gwal, A. K., and Huang, Y. N.: Nighttime enhancements in ionospheric electron content: seasonal and solar cycle variation, Ann. Geophysicae, 13, 256-261, 1995.

Tsurutani, B. T., Goldstein, B. E., Smith, E. J., Gonzalez, W. D., Tang, F., Akasofu, S. I., and Anderson, R. R.: The interplanetary and solar causes of geomagnetic activity, Planet. Space Sci., 38, 109-126, 1990.

Unnikrishnan, K., Balachandran Nair, R., and Venugopal, C.: Latitudinal variations of stormtime ionospheric response, Indian J. Phys., 70B, 5, 351-356, 1996.

Young, D. M. L., Yuen, P. C., and Roelofs, T. H.: Anomalous nighttime increase in total electron content, Planet. Space Sci., 18, 1165-1179, 1970. 